\title{
PROBIÓTICOS EM RAÇÕES PARA FRANGOS DE CORTE UTILIZANDO FARINHA DE CARNE E OSSOS COM DIFERENTES NÍVEIS DE CONTAMINAÇÃO BACTERIANA
}

\begin{abstract}
RESUMO - Com o objetivo de estudar os efeitos de probióticos no desempenho de frangos de corte consumindo dietas com farinhas de carne e ossos com diferentes contaminações bacterianas, foi realizado um experimento na Universidade Federal de Lavras, no qual foram utilizados 576 pintos da linhagem Hubbard, com um dia de idade, metade de cada sexo. O delineamento experimental foi inteiramente casualizado, num esquema fatorial 4 x 3 (rações e probióticos) com 4 repetições de 12 aves alojadas em baterias metálicas e o período experimental foi de 1 a 28 dias de idade. Os tratamentos foram constituídos de 4 rações, uma sem farinha de carne e ossos e com fosfato bicálcico (testemunha), e as outras três com farinhas de carne e ossos de alto $(1,0 \mathrm{x}$ $\left.10^{4}\right)$, médio $\left(4,5 \times 10^{3}\right)$ e baixo $\left(1,0 \times 10^{3}\right)$ teor de contaminação bacteriana. Cada uma dessas rações foi fornecida sem probiótico, ou com um probiótico com cerca de três bilhões de células viáveis por grama, que tem como agentes ativos o Lactobacillus acidophilus, Strep-
\end{abstract}

\author{
ANTÔNIO SOARES TEIXEIRA ${ }^{1}$ \\ JORGE DOS SANTOS CAVALCANTI ${ }^{2}$ \\ PAULO ROBERTO OST ${ }^{3}$ \\ NEUDI ARTEMIO SCHOULTEN ${ }^{4}$
}

TERMOS PARA INDEXAÇÃO: Probióticos, farinha de carne e ossos, contaminação, frangos de corte.

tococcus faecium e Sacharomices cerevisae, fornecido na ração na dose de $10 \mathrm{~g} /$ ton ou ainda com um probiótico que contém Enterococcus faecium, Lactobacillus acidófillus, Lactobacillus plantarum e Lactobacillus sp como agentes ativos, na concentração de $3 \times 10^{10} \mathrm{ufc} / \mathrm{g}$ do produto, adicionado na água nas primeiras 24 horas de vida dos pintinhos, na proporção de 1,33 g/L de água. Observou-se pela análise da variância dos resultados que não houve efeito dos tratamentos $(\mathrm{P}>0,05)$ sobre o ganho de peso e consumo de ração e na conversão alimentar, para as aves que consumiram a ração com baixa contaminação. A inclusão de farinha de carne e ossos nas rações melhorou a conversão alimentar para as aves que receberam a ração com alta e média contaminação, independente do uso de probiótico. Verificaram-se redução nos casos de diarréia durante a primeira semana de vida dos pintinhos, com o uso de probióticos, e aumento na incidência de diarréia, quando se utilizou farinha de carne e ossos com médio e alto nível de contaminação bacteriana.

\section{USE OF PROBIOTICS IN BROILER RATIONS CONTAINING BONE AND MEAT MEAL WITH DIFFERENT LEVELS OF BACTERIAL CONTAMINATION}

\begin{abstract}
Aiming to study the effects of probiotics on performance of broiler chickens fed on diets containing bone and meat meal with different levels of bacterial contamination, an experiment was carried out in the Federal University of Lavras . 576 one-day-old broiler chicken of the Hubbard line, of both sexes, were used. The experimental design was completely randomized, in a 4 X 3 scheme (4 rations
\end{abstract}

and 3 probiotics) with 4 replications, being 12 birds per plot, housed in cages. The treatments were made up of 4 rations, one with no meat meal and with bicalcic phosphate (check) and the other three with meat meal with high, medium and lower levels of contamination $\left(1.0 \times 10^{4}, 4.5 \times 10^{3}\right.$ and $\left.1.0 \times 10^{3} \mathrm{ufc} / \mathrm{g}\right)$, respectively. Each of these rations were fed: without probiotic; with a probiotic containing about 3 billion viable cells per

1. Engenheiro Agrônomo, D.Sc., Professor do Departamento de Zootecnia da UNIVERSIDADE FEDERAL DE LAVRAS/UFLA - Caixa Postal 37 - 37200-000 - Lavras, MG. asoarest@ufla.br

2. Zootecnista, M.Sc. em Zootecnia.

3. Zoottecnista , M.Sc., Estudante de Doutorado DZO/UFLA. pauloost@ig.com.br

4. Lic. Cienc. Agr., M.Sc., Professor da Escola Agrotécnica Federal de Rio do Sul - SC. neudi@navinet,com.Br 
gram of Lactobacillus acidophilus, Streptococcus faecium e Sacharomices cerevisae, at the a dose of 10 g/ton; and a probiotic containing Enterococcus faecium, Lactobacillus acidófillus, Lactobacillus plantarum e Lactobacillus sp., at the concentration of $3 \times 10^{10}$ $\mathrm{ufc} / \mathrm{g}$ of this product, added to water $(1.33 \mathrm{~g} / \mathrm{L})$ in the first 24 hours of chick's life. It was found that there was not any significant effects $(\mathrm{P}<0.05)$ on the weight gain, feed intake and feed conversion, for the birds fed on the ration with low level contamination. The inclusion of bone and meat meal resulted in a better feed conversion for the birds fed on the rations with high and medium contamination. It was observed a reduction on the appearance of diarrhea, during the first week chick's life, when the probiotics were used and an increase when bone and meat meal with medium and high level of contamination.

INDEX TERMS: Probiotics, meat and bone meal, contamination, broiler.

\section{INTRODUÇÃO}

A farinha de carne e ossos, subproduto de frigoríficos, tem tido sua produção incrementada nos últimos anos, devido ao aumento da produção pecuária. Entre os subprodutos de abatedouros e frigoríficos, a farinha de carne e ossos é a principal. A avicultura tem consumido grande quantidade desse produto, pois a mesma é boa fonte de aminoácidos, minerais e vitaminas, quando bem processada. Atualmente é usada principalmente como fonte de fósforo. A farinha de carne e ossos é um produto orgânico, altamente sujeito a contaminações. A falta de cuidados e de um adequado padrão de qualidade em seu processamento tem limitado seu uso nas rações iniciais para frangos de corte.

A maior preocupação dos nutricionistas tem sido a de veicular microorganismos patogênicos responsáveis por desordens entéricas, emplastamento e desidratação nas primeiras semanas de vida, ao utilizarem esse ingrediente na formulação da ração. Assim, numerosas pesquisas têm sido realizadas visando a detectar tais microorganismos e reduzir sua população, diminuindo assim os possíveis efeitos deletérios observados nas aves. A possível introdução de agentes infecciosos nas granjas por meio da farinha de carne e ossos tem merecido atenção de avicultores e técnicos, principalmente no que se refere a salmonelas (Oliveira et al., 1981). Via de regra, os microorganismos contaminantes são: clostrídios, salmonelas, coliformes, stafilococus, e pseudomonas (Nakano \& Cols, 1972; Silva \& Cols, 1973).

Aliado a esse efeito, sabe-se que na avicultura industrial moderna os pintinhos são praticamente estéreis do ponto de vista microbiológico. Isso se deve a sua produção em sistemas artificiais acépticos, em todas as fases do processo. O seu desenvolvimento intestinal e geral é afetado de forma marcante, pela falta de contato com uma microbiota natural logo após a eclosão. Para contornar esse problema, têm sido utilizados os chamados "promotores de crescimento", que, geralmente, são drogas antibióticas utilizadas de forma contínua na ração, em doses subterapêuticas, respeitando o período de carência. No entanto, é crescente o aparecimento de cepas bacterianas resistentes às drogas terapêuticas e, conseqüentemente, há menor disponibilidade das mesmas para tratamento. A isso, soma-se a pressão do melhoramento genético das aves, que as tem tornado cada vez mais vulneráveis aos patógenos.

Atualmente, grande parte da segurança alimentar está baseada no controle de resíduos nos alimentos, em decorrência do uso de pesticidas, drogas veterinárias e acidentes envolvendo contaminantes ambientais. Em razão das dúvidas e indícios de que a utilização de antibióticos como promotores de crescimento na produção animal possa estar provocando resistência dos microorganismos aos antibióticos utilizados na medicina humana, estão sendo impostas restrições e até mesmo banimento desses produtos na produção animal. Consumidores atentos a esses fatos são levados a procurar produtos livres de resíduos de aditivos.

Como alternativas, existem no mercado diferentes produtos que têm sido sugeridos para substituir os antibióticos como promotores de crescimento. Entre eles, os mais importantes são os probióticos e prébioticos como uma nova opção. Probióticos são descritos como microorganismos benéficos fornecidos na ração das aves como forma de melhorar o equilíbrio da microflora intestinal.

Esses probióticos são bactérias naturais do intestino, as quais, após uma ingestão em doses efetivas, são capazes de se estabelecer ou mesmo colonizar o trato digestivo e manter ou aumentar a flora natural, prevenindo a colonização de organismos patogênicos e assegurando uma melhor utilização dos alimentos (Vanbelle et al., 1990).

Trabalhando com promotores de crescimento para frangos de corte, Bertechini \& Hossain (1993) observaram ganho de peso e conversão alimentar sig- 
nificativamente melhores para os tratamentos com o antibiótico virginiamicina, probiótico Biobac e o antibiótico virginiamicina + probiótico, em relação ao controle. Porém, não foram observadas diferenças significativas nos parâmetros estudados entre os tratamentos com virginiamicina + probiótico, e os tratamentos com virginiamicina ou probióticos adicionados às rações isoladamente.

Dois experimentos com frangos de corte e um com poedeiras foram conduzidos por Suida (1994), para estudar a utilização do alho, do probiótico Calsporin e do quimioterápico Nitróvin, e observaram que o peso corporal e do ovo, para frangos e poedeiras, respectivamente, e o consumo de ração foram maiores para as aves alimentadas com ração contendo probiótico Calsporin e Nitrovin, em relação ao tratamento testemunha e ao alho. Também para avaliar o efeito de rações que continham antibióticos, quimioterápicos e probióticos no desempenho de aves de corte, Zuanon (1995) verificou que o consumo de ração diminuiu para as aves que receberam probióticos na ração inicial, enquanto as conversões alimentares das aves com Avoparcim 10 ppm e Colistina $10 \mathrm{ppm}+$ Avoparcim $10 \mathrm{ppm}$ foram significativamente melhores do que as das aves que receberam probióticos.

Dessa forma, objetivou-se com o presente trabalho estudar os efeitos do uso de probióticos fornecidos na primeira semana de idade na água ou continuamente na ração, sobre o desempenho e incidência de diarréia em frangos de corte, em rações contendo farinhas de carne e ossos com diferentes contaminações bacterianas em rações para frangos de corte.

\section{MATERIAL E MÉTODOS}

O experimento foi realizado no Setor de Avicultura do Departamento de Zootecnia da Universidade Federal de Lavras. Foram utilizados 576 pintos de corte Hubbard, com um dia de idade, vacinados contra as doenças de Marek e Bouba Aviária, sendo alojados em gaiolas com 12 pintinhos em cada unidade experimental, metade de cada sexo, de 1 a 28 dias de idade. $\mathrm{O}$ delineamento experimental foi o inteiramente casualizado, em esquema fatorial $4 \times 3$ (ração $\mathrm{x}$ probiótico) constituindo 12 tratamentos e 4 repetições, totalizando 48 unidades experimentais. As rações foram preparadas à base de milho, farelo de soja, óleo, calcário, premix mineral e vitamínico, farinha de carne e ossos e probióticos, de modo a serem iso- nutritivas, de acordo com as recomendações de Rostagno et al. (1994). Na Tabela 1 e 2 verifica-se a composição dos ingredientes e das rações experimentais, respectivamente.

Os tratamentos foram constituídos pelo fornecimento de cada uma das quatro rações experimentais às aves de três formas: a) sem adição de probiótico; b) com adição de dez g/ton de ração de um probiótico que continha como agente ativo o Lactobacillus acidophilus, Streptococcus faecium e Sacharomices cerevisae na concentração de três bilhões de células viáveis por grama; c) com fornecimento de um probiótico adicionado na água de bebida dos pintinhos nas primeiras 24 horas de vida, na proporção de $1,33 \mathrm{~g} / \mathrm{L}$ de água que continha Enterococcus faecium, Lactobacillus acidófillus, Lactobacillus plantarum e Lactobacillus sp, como agente ativo na concentração de 3 x $10^{10} \mathrm{ufc} / \mathrm{g}$.

Os dados referentes à média de ganho de peso, de consumo de ração e de conversão alimentar no período de 1 a 28 dias de idade foram submetidos à análise de variância utilizando o pacote computacional SAEG (Sistema de Análise Estatística e Genética) desenvolvido por Euclydes (1982), aplicando-se para as comparações das médias o teste de Student Newman Keuls (SNK). Foi avaliada, ainda, por contagem, a porcentagem de diarréias durante a primeira semana de vida dos pintinhos, uma vez que, dependendo da contaminação da ração, essa diarréia pode ser aumentada. As contagens foram feitas ao fim do dia, quando as bandejas coletoras de excretas eram retiradas e limpas.

A classificação da farinha de carne e ossos utilizada neste experimento foi realizada com base na contagem bacteriana, sendo considerada com alta contaminação aquela que apresentou $1,0 \times 10^{4} \mathrm{ufc} / \mathrm{g}$, com média contaminação com $4,5 \times 10^{3} \mathrm{ufc} / \mathrm{g}$ e com baixa contaminação com $1,0 \times 10^{3} \mathrm{ufc} / \mathrm{g}$. Essas farinhas foram selecionadas entre várias farinhas analisadas.

\section{RESULTADOS E DISCUSSÃO}

Os valores médios do consumo de ração, ganho de peso, conversão alimentar de 1 a 28 dias idade e a porcentagem de ocorrência de diarréia na primeira semana de vida são apresentados na Tabela 3. Em nenhuma variável houve interação $(\mathrm{P}>0,05)$ entre as rações e probióticos. Para a porcentagem de ocorrência de diarréia, não foi realizada a análise de variância. 
TABELA 1 - Composição dos ingredientes utilizados nas rações experimentais.

\begin{tabular}{lcccccccc}
\hline \multicolumn{1}{c}{ Ingrediente } & $\begin{array}{c}\text { EM } \\
\mathbf{K c a l / K g )}\end{array}$ & $\begin{array}{c}\text { PB* } \\
(\boldsymbol{\%})\end{array}$ & $\begin{array}{c}\text { MET } \\
(\boldsymbol{\%})\end{array}$ & $\begin{array}{c}\text { M+C } \\
(\boldsymbol{\%})\end{array}$ & $\begin{array}{c}\text { LIS } \\
(\boldsymbol{\%})\end{array}$ & $\begin{array}{c}\text { Ca* } \\
(\boldsymbol{\%})\end{array}$ & $\begin{array}{c}\text { P* } \\
(\boldsymbol{\%})\end{array}$ & $\begin{array}{c}\text { Na } \\
(\boldsymbol{\%})\end{array}$ \\
\hline Milho & 3416 & 7,74 & 0,17 & 0,35 & 0,23 & 0,06 & 0,21 & 0,021 \\
Farelo soja & 2283 & 44,45 & 0,65 & 1,34 & 2,87 & 0,29 & 0,54 & 0,091 \\
Farinha carne alta** & 1705 & 37,40 & 0,68 & 1,04 & 2,71 & 14,95 & 8,40 & 0,280 \\
Farinha carne média** & 1785 & 43,90 & 0,68 & 0,92 & 2,71 & 13,27 & 7,12 & 0,260 \\
Farinha carne baixa** & 1835 & 49,62 & 0,68 & 0,75 & 2,71 & 9,70 & 5,56 & 0,240 \\
Fosfato bicálcio & - & - & - & - & - & 23,67 & 18,33 & - \\
Calcário & - & - & - & - & - & 37,98 & - & - \\
Sal & - & - & - & - & - & - & - & 39,740 \\
DL - Metionina & - & - & 99,00 & 99,00 & - & - & - & - \\
Óleo de soja & 8786 & - & - & - & - & - & - & - \\
\hline
\end{tabular}

* Análise realizada no Laboratório de Nutrição Animal da UFLA, os demais foram retirados da tabela de Rostagno et al. (1994).

** Refere-se ao nível de contaminação bacteriana.

A análise de variância para os dados de ganho de peso e de consumo de ração no período de 1 a 28 dias de idade indicou que não houve influência tanto das farinhas de carne e ossos como dos probióticos utilizados $(\mathrm{P}>0,05)$. Resultados semelhantes foram observados por Silva (1999), quando estudou-se rações com probióticos para frangos de corte, na fase inicial, em que também não foi verificado efeito do probiótico sobre o ganho de peso das aves. Por outro lado, utilizando rações complexas, Lima (1988), diferentemente aos resultados observados neste trabalho, observou maior ganho de peso nas aves que receberam farinha de carne e ossos e farinha de peixe.

Os efeitos de probióticos sobre o consumo de ração obtidos nesse trabalho são semelhantes aos encontrados por Bertechini \& Hossain (1993), Suida (1994) e Zuanon (1995), que trabalharam com probióticos para aves na fase inicial da criação e, quando compararam com um grupo testemunha, não observaram efeito da adição do probiótico no consumo de ração. No entanto, Silva (1999), estudando rações com probióticos para frangos de corte, na fase inicial, verificou redução do consumo de ração das aves quando receberam probiótico.
Essa divergência de resultados, tanto para o ganho de peso como para consumo de ração, pode, em parte, ser explicada pela variação de desafios nos diferentes trabalhos, ou seja, nível de contaminação da cama, tipo e desinfecção das instalações e da localização do galpão. Em particular, neste trabalho, o fato de as aves terem sido alojadas em gaiolas deve ter contribuído para a redução do desafio, dificultando, assim, a observação de efeitos dos tratamentos aplicados.

Para a conversão alimentar, observa-se que quando as aves receberam a ração controle, elas apresentaram pior conversão alimentar, independentemente do uso de probióticos, ao passo que a inclusão de farinha de carne e ossos nas rações melhorou a conversão alimentar para as aves que receberam a ração com alta e média contaminação, e a conversão alimentar das aves que receberam ração com farinha de baixa contaminação não diferiu $(\mathrm{P}>0,05)$ da ração controle, independente do uso de probiótico, quer na água ou ração. Isso ocorreu provavelmente devido à maior inclusão de farinha de carne e ossos de baixa contaminação (Tabela 2), que possivelmente sofreu um excessivo processamento térmico, piorando, assim, seu valor nutricional, principalmente no que diz respeito à digestibilidade de aminoácidos. Resultados

Ciênc. agrotec., Lavras. V.27, n.4, p.927-933, jul./ago., 2003 
divergentes para a conversão alimentar foram observados por Bertechini \& Hossain (1993) e Silva (1999), quando estudaram rações com probióticos para frangos de corte, na fase inicial, em que foi verificado melhora da conversão com a utilização do probiótico. Por outro lado, Suida (1994) e Zuanon (1995) não encontraram diferenças significativas.

TABELA 2 - Composição das quatro rações experimentais.

\begin{tabular}{|c|c|c|c|c|}
\hline \multirow{3}{*}{ Ingrediente } & \multicolumn{4}{|c|}{ Rações } \\
\hline & \multirow{2}{*}{ Controle } & \multicolumn{3}{|c|}{ Nível de contaminação bacteriana } \\
\hline & & Alta & Média & Baixa \\
\hline Milho & 56,694 & 60,426 & 60,156 & 61,076 \\
\hline Farelo de soja & 37,360 & 33,700 & 32,000 & 29,700 \\
\hline Farinha de carne & - & 4,200 & 4,950 & 6,400 \\
\hline DL -metionina (99\%) & 0,177 & 0,190 & 0,190 & 0,190 \\
\hline Óleo vegetal & 2,368 & 1,800 & 1,500 & 1,500 \\
\hline Calcário & 1,096 & 0,900 & 0,850 & 1,000 \\
\hline Fosfato Bicálcico & 1,871 & --- & - & - \\
\hline Sal iodado & 0,300 & 0,300 & 0,300 & 0,300 \\
\hline Premix Vitamínico ${ }^{1}$ & 0,030 & 0,030 & 0,030 & 0,030 \\
\hline Premix Mineral $^{1}$ & 0,050 & 0,050 & 0,050 & 0,050 \\
\hline Cloreto de Colina (60\%) & 0,024 & 0,024 & 0,024 & 0,024 \\
\hline Total & 100,0 & 100,0 & 100,0 & 100,0 \\
\hline \multicolumn{5}{|l|}{ Nutriente } \\
\hline E.M. (Kcal/Kg) & 3000,000 & 3008,933 & 3002,890 & 3005,405 \\
\hline Proteína Bruta (\%) & 21,000 & 21,020 & 21,051 & 21,806 \\
\hline Metionina (\%) & 0,495 & 0,503 & 0,506 & 0,506 \\
\hline Metionina + cistina $(\%)$ & 0,846 & 0,846 & 0,846 & 0,838 \\
\hline Lisina $(\%)$ & 1,165 & 1,132 & 1,132 & 1,114 \\
\hline Cálcio (\%) & 0,990 & 1,093 & 1,098 & 1,000 \\
\hline Fósforo disponível (\%) & 0,450 & 0,455 & 0,452 & 0,452 \\
\hline
\end{tabular}

${ }^{1} O$ premix forneceu por kg de ração: vit. A - 7.000 UI; vit. $D_{3}-1,500$ UI; vit. E - 12 UI; vit. $\mathrm{K}-1,5 \mathrm{mg}$; Vit. $B_{1}$ - 1,6 mg; vit. $B_{2} 5 \mathrm{mg}$; vit. $B_{6} 2,6 \mathrm{mg}$; vit. $B_{12} 10 \mu \mathrm{g}$; Niacina - $35 \mathrm{mg}$; Ác. Fólico - 0,7 mg; Ác. Pantotênico $13 \mathrm{mg}$; Se - 0,3 mg; Metionina - 1,0 g; Agente anticoccidiano - 0,06 g; promotor de crescimento - 0,04 g; Antioxidante - 0,02 g; Mn - $75 \mathrm{mg}$; Zn - $50 \mathrm{mg}$; $\mathrm{Cu}-8 \mathrm{mg}$; I - 0,75 mg; Fe - 50 mg. 
TABELA 3 - Médias de ganho de peso (GP), consumo de ração (CR), conversão alimentar (CA) de 1 a 28 dias de idade e ocorrência de diarréia na primeira semana de idade, conforme as farinhas de carne e ossos e probióticos utilizados.

\begin{tabular}{lcccc}
\hline \multicolumn{1}{c}{ Rações } & \multicolumn{3}{c}{ Variáveis } \\
\cline { 2 - 5 } & GP $(\mathbf{g})$ & CR $(\mathbf{g})$ & CA & Ocorrência Diarréia $(\%)$ \\
\hline Controle & $1018,27 \mathrm{a}$ & $1808,58 \mathrm{a}$ & $1,77 \mathrm{~b}$ & 5,5 \\
Farinha de carne alta & $1035,70 \mathrm{a}$ & $1784,01 \mathrm{a}$ & $1,72 \mathrm{a}$ & 12,5 \\
Farinha de carne média & $1047,20 \mathrm{a}$ & $1815,81 \mathrm{a}$ & $1,73 \mathrm{a}$ & 11,1 \\
Farinha de carne baixa & $1015,70 \mathrm{a}$ & $1771,40 \mathrm{a}$ & $1,74 \mathrm{ab}$ & 6,3 \\
\hline Probióticos & & & & 13 \\
\hline Ausência de probiótico & $1027,53 \mathrm{a}$ & $1804,91 \mathrm{a}$ & $1,76 \mathrm{a}$ & 5,2 \\
Probiótico na ração & $1031,77 \mathrm{a}$ & $1797,12 \mathrm{a}$ & $1,74 \mathrm{a}$ & 8,3 \\
Probiótico na água & $1028,36 \mathrm{a}$ & $1782,82 \mathrm{a}$ & $1,73 \mathrm{a}$ & 8,8 \\
\hline Média Geral & 1029,22 & 1794,95 & 1,74 & 2,590 \\
\hline Coeficiente de Variação & 3,793 & 3,678 & & \\
\hline
\end{tabular}

Médias seguidas de letras diferentes na mesma coluna diferem pelo teste $\mathrm{SNK}(\mathrm{P}<0,05)$.

$\mathrm{Na}$ literatura, encontram-se resultados bastante conflitantes, como os encontrados por Vanbelle et al. (1990), o que possivelmente ocorre em virtude de diferenças na qualidade de ingredientes e condições de desafio.

Lima (1988), comparando rações com e sem farinhas de origem animal, não encontrou nenhum efeito sobre a conversão alimentar para frangos de corte, o que discorda, em parte, dos resultados do presente trabalho.

Era esperado que os efeitos benéficos do uso de probióticos aparecessem nas primeiras quatro semanas de vida, período em que a microflora intestinal está sendo constituída (Dale, 1992). Entretanto, neste experimento, isso não foi observado, possivelmente pela falta de desafio nas condições experimentais.

As pesquisas com probióticos mostram muitas divergências nos seus resultados, tanto que, Charles \& Duke (1978) concordam que dificilmente se consegue confirmar os resultados quando se repete um mesmo experimento.

Observando a Tabela 3, verifica-se que numericamente há redução nos casos de diarréia, durante a primeira semana de vida dos pintinhos, quando se usa o probiótico. Além disso, também se observa aumento numérico na incidência de diarréia, quando se utiliza farinha de carne e ossos com médio e alto nível de conta- minação bacteriana, comparado à ração sem farinha de carne e ossos e ração com farinha de carne e ossos com baixa contaminação. Pelos resultados acima citados, percebe-se que a incidência de diarréia está diretamente relacionada com a contaminação do alimento.

\section{CONCLUSÕES}

Nas condições em que foram realizados este experimento, pode-se concluir que:

a) A utilização de farinha de carne e ossos de alta e média contaminação melhorou a conversão alimentar das aves.

b) A utilização de probiótico, tanto na água como na ração, não melhorou o desempenho das aves.

\section{REFERÊNCIAS BIBLIOGRÁFICAS}

BERTECHINI, A. G.; HOSSAIN, S. M. Utilização de um tipo de probiótico como promotor de crescimento em rações de frangos de corte. In: CONFERÊNCIA DE CIÊNCIA E TECNOLOGIA AVÍCOLA, 1993, Santos. Anais... Santos: Apinco, 1993.p. 1. 
CHARLES, O. W.; DUKE, S. The response of Laying Hens to Dietary Fermentation productions. Poultry Science, Georgia, v. 57, n. 5, p. 1399-1406, 1978.

DALE, N. Probióticos para aves. Avicultura Profesional, Georgia, v. 10, n. 2, p. 88-89, 1992.

EUCLYDES, R. F. Sistema para análises estatísticas SAEG. Viçosa: UFV, 1982. 59 p.

LIMA, C. A. R. Planos de alimentação e tipos de dieta para frangos de corte. 1988. 88 f. Dissertação (Mestrado em Nutrição de Monogástrico) - Universidade Federal de Lavras, Lavras, 1988.

NAKANO; COLS. Eficiência bacteriana e promotora de crescimento em aves do policoctu - poliamino - etilglicina e polioxieltileno - aquil - fenol - éter, quando adicionado à ração. In: CONGRESSO LATINO AMERICANO DE AVICULTURA, 1972, Brasília. Anais... Brasília: UBA, 1972.

OLIVEIRA, B. L.; FREIRE, F. G. G.; CAMPOS, E. J.; LAMAS, J. M. S. Doenças de aves diagnosticadas em dois laboratórios de Belo Horizonte, entre 1975 e 1980. In: CONGRESSO BRASILEIRO DE AVICULTURA, 7., 1981, Belo Horizonte. Anais... Belo Horizonte: UBA, 1981. v. 2, p. 248-259.
ROSTAGNO, H. S.; SILVA, D. J.; COSTA, P. M. A.; FONSECA, J. B.; SOARES, P. R.; PEREIRA, J. A. A.; SILVA, M. A. Composição de alimentos e exigências nutricionais de aves e suínos: tabelas brasileiras. Viçosa: UFV, 1994. $60 \mathrm{p}$.

SILVA, E. N.; COLS. Salmonelas em farinhas de origem animal destinadas à fabricação de rações. In: CONGRESSO BRASILEIRO DE AVICULTURA, 1973, Brasília. Anais... Brasília: UBA, 1973. p. 123-125.

SILVA, E. N. Probióticos em ração para frangos de corte. 1999. 66 p. Dissertação (Mestrado em Nutrição de Monogástricos) - Universidade Federal de Lavras, Lavras, 1999.

SUIDA, D. Estimulantes do desempenho de galinhas poedeiras e de frangos de corte. $1994.59 \mathrm{f}$. Dissertação (Mestrado em Nutrição de Monogástrico) - Universidade Federal de Viçosa, Viçosa, 1994.

VANBELLE, M.; TELLER, E.; FOCANT, M. Probiótcs in animal nutrition: a review. Archives of Animal Nutrition, Louvaini, v. 46, n. 7, p. 543-567, 1990.

ZUANON, J. A. S. Efeito de promotores de crescimento de frangos de corte. 1995.70 p. Dissertação (Mestrado em Nutrição de Monogástricos) - Universidade Federal de Viçosa, Viçosa, 1995. 